\title{
Capturing worlds
}

\author{
Julie Innes \\ University of Westminster \\ 41B Lancaster Avenue, London SE27 9EL \\ julie@julieinnes.com
}

\begin{abstract}
This paper uses psychoanalysis to explore the magic of the immersive experience, comparing $18^{\text {th }}$ century peepshows with the latest in virtual reality. A project to produce a museum artefact based on an existing antique peepshow, is the driving force behind this research to rediscover the enchantment of the peepshow, and to question how new technologies can add to this experience.
\end{abstract}

Peepshow. Virtual reality. PSYCHÉ. Psychoanalysis. Immersion.

\section{INTRODUCTION}

This research was inspired by the brief to build a museum artefact based on an existing $19^{\text {th }}$ century peepshow at the Brunel Museum, London. There are many possibilities of extending the peep show including the use of new technology - 3D CGI footage, stereoscopy, interactivity, light and sound - but I was charmed by the magic of the peepshow, and wary of losing this magic with the seduction of modern technology.

Before I began this project I wanted to understand the illusory pleasures of the traditional peepshow, and how modern technology could contribute. My research took me to an exhibition of peepshows from the collection of Werner Nekes, Ars Electronica in Linz, and to visit PSYCHÉ (CAVE) at the Cyberpsychology Lab, Université du Québec. I wanted to experience the illusions, old and new, first hand, and to consider the charms and weaknesses of both.

From this wider survey, I chose to compare two of the artefacts: Earthquake in Lisbon, Engelbrecht (1760) and PSYCHÉ (2008); both part of a continuum of the scientific and artistic quest for the immersive experience. The main framework for the comparison is psychoanalysis, which provides meaningful insight into the pleasures and mechanisms of their illusions. Comparison of the two artefacts produces a fruitful analysis of their strategies, as well as an understanding of the limits and possibilities for various methods of production available for the development of the contemporary peepshow.

\section{CASE STUDIES}

\subsection{Earthquake in Lisbon}

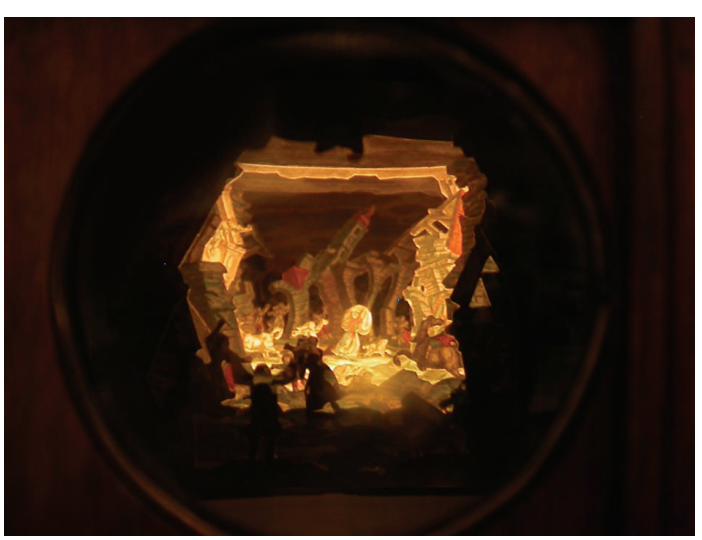

Figure 1: Earthquake in Lisbon, 1760, Martin Engelbrecht, collection of Werner Nekes

You enter a large white room in a gallery containing several old wooden boxes and various other paintings and drawings on the wall as part of a curated exhibition. Other people are milling about, quietly observing the artwork, and stepping up to peep into the wooden boxes.

Earthquake is a vertical box, about one meter high and $25 \mathrm{~cm}$ wide, with a circular lens at the top of the front panel. The craftsmanship of the box is quickly observed, but it is the window inside instantly attract your attention, and curiosity quickly compels you to take a look. Inside the box is a world in turmoil. Buildings topple, and people run for cover, the images almost seem to move as a light passes quickly through the scene, illuminating various events happening at different depths of the scene. 
Several aspects of this visual experience are instantly wonderful: the visual plane unexpectedly extends backward rather than vertically; the sense of drama and animation created by the moving light; the hugeness of this world trapped inside this small box.

You then take a step back from the world you have fallen into, and look for an explanation: hidden mirrors, light sources, the lens. It starts to make sense, you understand what you are looking at, and the second viewing inside allows you to take in the scene, read the narrative, and observe more closely the events depicted as the light passes through. You can also enjoy the charm of the hand tinted prints that compose the scene.

While your face is at the lens this view belongs to you, it is your private show that others are waiting for a chance to see, so you absorb all that you can before moving on to the next hidden world.

\subsection{PSYCHÉ}

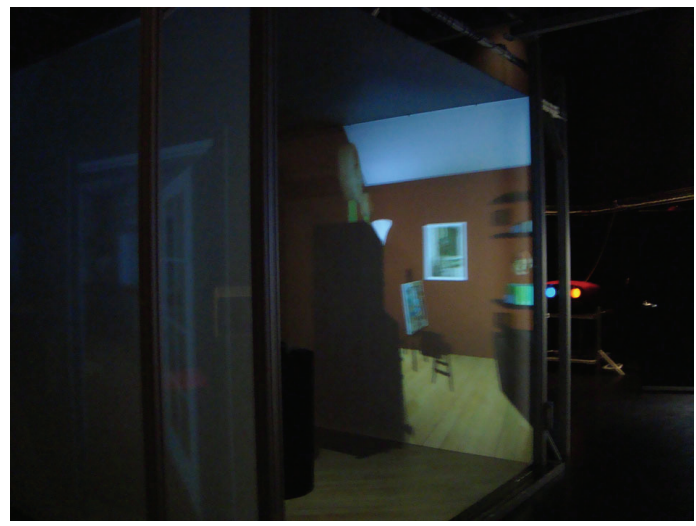

Figure 2: PSYCHÉ 2008, Cyberpsychology Lab Université du Québec en Outaouais, Canada

Before you enter the PSYCHÉ it is explained to you that you are about to enter a six sided room, with projections on each side to create the illusion of another three-dimensional space: an apartment with several rooms. You will be wearing goggles that produce a stereoscopic effect to enhance the illusion, and using a joy stick to control navigate around the space. Your own movement within the six walls will also be a part of the illusion of movement. At all times you will be in contact with the operator/therapist via an earpiece.

It is good to know all this, because it is quite a foreign experience to be shut inside a cube with high tech equipment strapped to your body. You are both excited by the prospect of such a new experience, but also slightly intimidated by the equipment and the monitoring of your own performance.
As the projections are switched on you can't help but notice the simple low-poly graphics do not match up to the usual experience of 3D graphics at the cinema, and you look for the seams between the walls to see how the visual space maps onto the real space. But now it's your turn, it is your navigation of the space that will bring this illusion to life. You start to explore the different rooms in the apartment, and slowly get used to this strange world where space works with slightly different rules. You want to be convinced by this illusion, but it still feels awkward, and you wonder if with time and practice you would get used to it.

There are moments though when all doubt disappears. To your amazement, you actually find yourself jumping out of the way as your poor navigation brings a kitchen counter hurtling towards your stomach, and a doorway threatens to shave off your right arm. During these happy, adrenalinefilled accidents the illusion is more than convincing. The six walls disappear, and space is filled with threateningly real three-dimensional objects.

\section{THE PLEASURES OF ILLUSION}

Both of these artefacts use mostly visual means to create an illusion of another space. However, the successes and pleasures of each artefact are quite different. This is partly due their different target audiences, but it is also dependent on the means of production available. The purpose of Earthquake is to entertain the viewer with simple trickery, and the delights of another world. The therapeutic use of PSYCHÉ requires a more convincing illusion, so that the user can revisit or act out situations in a way that is meaningful to them.

\subsection{Omnipotence: wish fulfilment and secrecy}

A wider survey of early peep shows makes it clear that an important part of their role was as a window into otherwise hidden worlds. Major world events such as earthquakes and battles were depicted, as well as spectacles usually only for the eyes of the privileged such as grand exhibitions and masked balls.

When you lean forward to peep into the window of Earthquake, you become the privileged spectator of a hidden world. The excitement you feel reminds you of the childhood experiences of creating worlds, houses, theatres in boxes. As an adult you feel one step removed from this, you do not project yourself with blind faith into this world as a child might, yet the magic is still there.

In Magic and the Aesthetic Illusion Leon Balter considers the psychological desire for magic, and explains this difference in terms of ego maturation. He states that magic expresses the aim to change 
or control objects in the external world; you wish for something to happen and somehow it does (Balter, 2001, pp. 1171-4). The pleasure of this sense of omnipotence is very primitive and infantile, stemming back to the mysterious fulfilment of our base needs as children: I want food and it magically appears. But as adults we understand that the world does not really work like this, our egos are kept in check, and we understand that this is an overvaluation of our mental processes. The real world does not bend to our command and fulfil our every wish. Yet as rational adults we do not completely abandon our belief in magic, and Geza Rohiem writing in the 1950s extended Freud's theories on the psychoanalysis of magic to explain this. Roheim claims that magic is the basis of any thought that concerns agency in the external world, and that as the ego matures magic is not eradicated by our more realistic and practical understanding of the world. Although our conscious belief in magic may be inhibited, it is still an essential part of our belief in our own abilities: 'magic actually helps practical, knowledgeable people overcome external obstacles and internal inhibitions that impede their realistic endeavours' (Balter, 2001, p. 1171).

When you view Earthquake you are not magically transported back in time to witness this dramatic event in Lisbon, the real magic is in the instant illusion of space, created by light and shadow. In the book Devices of Wonder, Barbara Marie Stafford explains that our attraction to light and shadow has biopsychological factors, due its role in depth perception, and ultimately human survival (Stafford, 2001, pp. 67-69). Beyond the imagery therefore, the space and depth of Earthquake is a profound illusion.

Although this illusion can be quickly deconstructed by the rational adult mind, the delight that you can still be tricked in this way supports your inhibited belief in magic. An invigorating sense of omnipotence is felt because any experience of illusion or magic supports a deeper need to believe in your own possibility to produce change in the external world.

What's more, you can indulge this infantile fantasy in secret. While you behold the illusion inside the box, you are there alone, no-one else can see inside, and your experience of the illusion is personal and private. PSYCHÉ is quite different in this aspect: although you are alone inside the six walls, your experience is not private. You are being monitored from outside and have become in fact part of the installation, with your personal experience actually being an important outcome of the session.
Privacy is an important part of the pleasure that can be experienced in illusion. As Balter explains, the illusion may allow you to entertain infantile fantasies but they are still not socially acceptable. He quotes Freud, 'the adult...is ashamed of his phantasies and hides them from other people...ashamed of his phantasies as being childish and unpermissable' (Balter, 2001, p. 1183). The aspect of secrecy afforded by the peepshow means that although the illusion can be easily deconstructed by your rational adult mind, there is a deep pleasure produced by being allowed to revel privately in your own sense of omnipotence.

PSYCHÉ may not provide this same sense of intimacy and privacy, but it reinforces your sense of omnipotence in other ways. The interactive nature of the installation makes it possible for your wishes to be magically fulfilled: you want to enter another room and as you move the illusion transforms and provides you with that room. Your adult mind does not really allow you to indulge in this illusion completely, most of the time you are still aware of the 3D graphics and the flimsy cube surrounding you, but there are moments when this all disappears and the illusion seems complete. When your instinct makes you jump out of the way of moving objects, your heart beats faster, and for a short time you have been completely fooled. In this way, interactivity has produced physical evidence that the illusion of the apartment in the PSYCHÉ is compelling - in a way that the peep show is not.

In his paper Representation, Illusion and the Cinema, Richard Allen makes a useful distinction between illusions that are compelling and illusions that are not. A compelling illusion is one where although your rational mind understands that this is not real, the illusion still persists: the deception is involuntary and unavoidable (Allen, 1993, p. 36). A clear visual example of this is in the Müller-Lyer perspective illusion (Figure 3 ), where two lines can be measured to be exactly the same length, yet one continues to appear to be much longer than the other. This experience is not unlike jumping out of the way of a wall that you know does not exist in the illusion of PSYCHÉ.

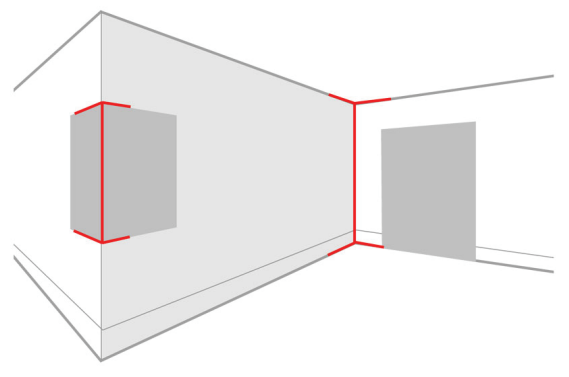

Figure 3: The Müller-Lyer Illusion 
The compelling nature of this illusion powerfully reinforces our inhibited belief in magic, boosting a sense of omnipotence, and freeing us from the restraints of adult society and institutions (Balter, 2001, p. 1185). Beyond the limits and practicalities of adult life there extends a world of possibilities, and this is proof.

The Earthquake cannot provide us with even a moment where the illusion is so compelling. The peepshow is more like the mirror illusion that Allen describes in contrast to the Müller-Lyer illusion, where a hidden mirror can temporarily deceive the viewer. A mirror that is concealed in an apparatus or architecture can initially trick the adult viewer into an altered perception of space, but as soon as you understand the deception, the sense of illusion is lost and cannot be restored (Allen, 1993, p. 36).

In terms of omnipotence, the ultimate aesthetic illusion would be one that combines the secrecy and intimate experience of the world inside the peepshow, with the powerfully compelling nature of the vital moments of PSYCHÉ.

\subsection{Recathexis: 'real-life', but safer}

These compelling moments that provoke psychological and physical reactions in PSYCHÉ, are a powerful feature of the possibilities that modern technology brings to the immersive experience. Three-dimensional moving images and interactivity seem to be able to provoke reactions from the viewer that suggest a complete but momentary belief in the illusion: the illusion has become reality.

Reliving past experiences has a direct therapeutic use, and an important part of the development of virtual reality has been for the treatment of phobias and post-traumatic stress, as well as training for the military such as submarines and cockpits.

In The mad scientists: Psychoanalysis, dream and virtual reality' Marie Leclaire uses Freud's analysis of dreams to explore the psychological mechanisms of virtual reality. Freud's premise is that perceptions and motor actions leave psychic traces, and that those that are pleasurable hold a privileged psychological status: they can be returned to the consciousness to reduce tension in the future (2003, p. 337). This recathexis of perception explains the pleasure to be felt from dreams and hallucinations.

But, as Leclaire points out, there are two big differences between dreams and virtual reality: the involvement of the ego, and the engagement of motor functions. In waking life the ego is actively involved in cathexis of perception, but in sleep there is an active decathexis, as its interests are displaced by the desire for sleep. Sleep liberates dreams from serving the interests of the ego. Sleep also disconnects motor functions from psychic activity; we do not physically act out our dreams, so that impulses usually inhibited in waking life become harmless in our dreams (Leclaire, 2003, pp. 337-338). This is an important feature of PSYCHÉ; the ego is still actively involved in mental processes, and at the same time motor actions can be explored in safety. This means that the desires of the ego can be investigated by the therapist through the analysis of perception and motor functions. Not only can existing memories of experiences be revisited and explored, but they can be replaced by the cathexis of new more pleasurable perceptions.

Earthquake and PSYCHÉ make good use of different psychological pleasures of illusion, but neither manages to truly maintain the magic throughout the entire viewing experience. The pleasure of Earthquake is instant, and although the illusion can continue to engage the viewer, it is not compelling but voluntary and avoidable. PSYCHÉ, however, can be extremely compelling causing the viewer to respond physically and psychologically at times. This illusion though tends to be fragmented, and perhaps more dependent on the previous experience of the viewer. By exploring the mechanisms of the aesthetic illusion in the next chapter, I hope to understand how each artefact operates to produce its own distinctive pleasures, and to consider the possible limitations of each.

\section{PRODUCING AND MAINTAINING ILLUSION}

Balter describes the aesthetic illusion as a combination of two illusions: '(1) that the daydream embodied by the work of art is the beholder's own, the artist being ignored, and (2) that the artistically described protagonist is a real person with a 'real' world' (2001, p. 1163). For the first illusion 'this is my daydream', there is a history of well developed strategies in literature, art and film to fall back on; but the second illusion 'the real person in a real world' presents a more complex creative problem.

\subsection{This is my daydream: universality, intimacy and ownership}

A key mechanism for the production of this first illusion is that the artist uses 'nearly universal ('typical') fantasy structures that embody unconscious infantile fantasies of an extremely stimulating kind' (Balter, 2001, p. 1177). In this way, the instinctual excitement generated becomes so personal that the artist's fantasy becomes mistaken as the viewer's own, and the hand of the artist is forgotten: 
The beholder daydreams the artists proffered daydream, then mistakes the artists dream for his/her own, thus imagines and tacitly claims a creators proprietorship over the daydream embodied in the work of art (Balter, 2001, p. 1185).

As already described, the infantile fantasy of omnipotence is played out in both Earthquake and PSYCHÉ in different ways. Earthquake transports you to an exciting world event, from which you heroically return unscathed; and the interactive visual illusion transforms to obey your wishes in PSYCHÉ.

The intimate nature of the peepshow strengthens the sense of 'my daydream'. When you peer into a small, closed world made of wood and line drawings on paper, you have a real sense that you are the single privileged viewer of this illusion, and even that you could have made it yourself: it could belong to you. In the $18^{\text {th }}$ and $19^{\text {th }}$ centuries, although most often displayed by travelling showmen, it was possible to own a peepshow and purchase cards with various illusions from printers. While some peepshows had multiple peepholes, most had only one or two and offered a very individual private experience in an often very public space (Balzer, 2001, p. 14). Miniature peepshows completely constructed of printed paper, that concertinaed flat, could be bought at tourist attractions, making ownership of the illusion literal.

While the interactive and transformative nature of $P S Y C H E$ experience produces a powerful sense of omnipotence and ownership of the 'daydream', in some ways the context and practicalities of PSYCHÉ can act to undermine this and distance the viewer from the illusion. When you first enter the lab you are very aware that PSYCHÉ is a large, complex and expensive creation that belongs to someone else. The goggles and joystick are a slightly awkward but essential part of the experience. Interactivity produces a level of authorship that suggests 'my daydream', but also adds an element of foreignness: you move through space, yet not in the way that you are accustomed to. The scene changes as you step forward, but only to the limit that the real walls of PSYCHÉ will allow. Navigation of the illusory space requires an unfamiliar co-ordination of your feet and the joystick controls, and this unfamiliarity is a constant reminder that you are inside someone else's fantasy: the artist is not forgotten. The foreignness of this needs be overcome, either through mastery of the controls or an interface that is more intuitive, so that the illusion can belong more completely to the beholder.

In the same way, the line drawings of Earthquake can act as a constant reminder of 'the hand of the artist'. In Representation, Illusion, and the Cinema,
Allen describes Wollheim's concept of 'seeing-in' versus 'seeing-through', in terms of paintings and photographs (1993, p. 22). 'Seeing in' is actually about the capacity to determine figure-ground relationships in the surface and mark making of the artist, whereas the original object is more present 'seeing-through', and the role of the artist is diminished.

The line drawings of Earthquake require 'seeing-in', but there are also aspects of Earthquake that facilitate this. Objects are cut out an isolated from the background, and the parallaxing that occurs when the head is moved makes these relationships clear. Shadows created by light effects also mark out objects and figures from the background. This makes 'seeing in' easier, distracting the viewer from the both the hand of the artist and reinforcing the illusion.

But although this experience of $3 D$ is an important part of the illusion, mimicking the 'real' and helping the viewer with 'seeing in', it is also uncanny. There is something not quite right with the physics of the scene. Although it relates to some of our real world experience of light, the flatness of the shadows between the layers draws attention back to the surface of paper, and to the lack of threedimensional rotation of the objects.

The CGI of PSYCHÉ attempts to solve this problem. The three-dimensional, stereoscopic imagery is created only on one layer, to be projected onto one flat surface that is not intended to be read by the viewer as part of the illusion. The real surface should remain invisible, and does not contribute to the reading of the image. The 3D effect is generated by the movement of the head creating the rotation of the objects in the scene, and shadows are algorithmically calculated to fall convincingly between objects. In this way, even low resolution graphics take us a step closer to 'seeing through' rather than 'seeing in'.

Modern technology has greatly expanded possibilities for interactivity and methods of image generation, but their use should be carefully considered to promote a sense of intimacy, personalisation and ownership of the fantasy in the aesthetic illusion.

\subsection{Real person in a real world: lack of proxy and reality testing}

While infantile fantasies of omnipotence may provide the artist with reliable access to the viewer's instinctual excitement, they are also inevitably accompanied by less pleasurable side effects, and the artist needs a strategy to manage these. Infantile fantasies tend to be incompatible with adult mental life, and so unpleasant side 
effects are produced: anxiety, shame, and guilt (Balter, 2001, p. 1177). These anxieties are in fact the motivation for the second illusion of 'real person in a real world', and this is why this second illusion is not possible without the first. The belief in the reality of the protagonist (and the protagonist's world), allows the viewer to experience the illusory world vicariously rather than directly: the viewer can indulge in the pleasures of the illusion through identification with the protagonist, but deflect anxieties onto this proxy who remains 'the other' (Balter, 2001, p. 1187).

An important feature of both Earthquake and $P S Y C H E$ is that there is no protagonist: the viewer experiences the fantasy world directly. This does not necessarily make the complete aesthetic illusion impossible, but it renders it fragile and unstable.

In PSYCHÉ you become the protagonist, it is your body that is moving through this virtual space and leading the narrative. There is no proxy to provide the comforting distance from the guilt and anxiety produced by your infantile indulgence. The conscious ownership of your personal illusion of omnipotence leads you to be very critical: looking for gaps in the illusion. In the same way, the illusion of Earthquake rewards you with the pleasures of the omnipotence of a god-like view, but deprives you of the relief of a proxy, and for this reason the illusion is only partial 'this is my daydream', and is short lived. If there is no proxy relationship (either because identification with protagonist is too strong and direct, or because there is no protagonist), the viewer must experience these anxieties directly, which can be overwhelming and result in a complete breakdown of the illusion (Balter, 1999, p. 1322).

One thing to consider in terms of Earthquake is the fact that in their original context peepshows were usually displayed by a showman who would guide the viewer with dramatic narration (Balzer, 1999, p. 14). This narration is not available to the contemporary viewer, but it is possible to imagine that a good showman could produce a sense of identification for the viewer, with the role of protagonist shifting through various characters in the scene. This type of identification is particularly evoked by other peepshows such as 'party at the palace', where multiple scenarios are being enacted by lively characters. This type of narrative guidance is also available to most users of the PSYCHÉ, where motive and context would be provided by the therapist.

Identification and emotional engagement have a direct effect on the motivation of the viewer to invest in the belief of the reality of the illusory world, and so any feature of the installation that can intensify the instinctive emotional reaction of the viewer will also act to stabilise the sense of 'real world'.

The perception of reality is a complex mental process where the ego employs 'reality-testing' to distinguish perceptions of the external world from what is represented internally. Freud considered hallucination to be the primary state: that perception initially relies upon the cathexis of mnemic traces produced by past perceptions; and that the ego employs reality-testing to step in and inhibit this cathexis, looking instead to the external world for 'indications of reality'. Freud's indications of reality are binary: what is represented either is accompanied by an indication of reality, or it is not. The problem with this is that this does not allow for the sense of 'it's only a dream': an experience that can be perceived as real on one level, but at the same time not real (Leclaire, 2003, pp. 337-339). Leclaire expands on the concept of reality-testing to allow for this, adding 'indications of immediacy' to the concept of reality testing. A representation can initially have indications of immediacy, and indications of reality will only appear if these indications of immediacy are inhibited by the investigation of the ego:

\begin{abstract}
Indications of immediacy are governed by a binary process (all or nothing), indications of reality flow from a complex activity constituted by action and thought. A convergence of perceived, represented and motor memories is the precondition for an indication of reality (Leclaire, 2003, p. 341).
\end{abstract}

This complex process of judgement means that the desires and motivations of the ego have an important role to play in our perception of reality, and the belief in a person or a world as 'real'.

It is these complexities that allow the aesthetic illusion to become complete and 'real'. A simpler, more binary notion of reality would never allow the artistic creation to produce indications of reality: there are just too many levels on which artwork cannot compare to our external world. The 'real world' of the illusion is not literally the same real world of the viewer, but one that the ego is motivated to believe, and that makes sense in its own terms.

Allen explains this sense of parallel reality in his discussion of the projective illusion. He describes the three possible ways of viewing a zombie film: you may perceive a fictional zombie recorded on film (denying its reality completely), you could see it as a recording of animals that really exist, or the third option is that you perceive a world of zombies. You do not mistake the film for actuality, but you forget that you are watching a film. This is not a compelling illusion, but one where you choose to 
allow the illusion to persist and to enter this parallel reality. The three things that help to produce this projective illusion are that the projection has no surface, use of diegetic sound, and that there is no edge to the image (Allen, 1993, pp. 40-41).

Unlike Earthquake, PSYCHÉ fulfils all these requirements: the screens/walls of the CAVE disappear, sound accompanies the imagery, and illusion extends all around you. However, as Allen points out, the viewer chooses to allow the alternate, illusory world to exist, and this choice is motivated by the viewer's emotional instinctual involvement. This in turn is influenced by the viewers expectations based on past experiences, and the categorisation of the CAVE as a virtual reality installation means that it has a lot to live up to. The therapist or artist may have strategies to engage the viewer emotionally, but the expectations of virtual reality are built from past perceptions of fictional machines such as the Holodeck in Startrek. You hope that you will find yourself in an alternate, virtual reality that is a literal replica of your external world, and that the graphics will be at least as convincing and sophisticated as those you have already seen in 3D at the cinema. These past perceptions form a part of the desires of the ego, and mean that it is less likely to allow the CAVE to produce 'indications of reality', that will allow the experience to be believable.

Earthquake also reflects the complexities of perception and reality. After the initial illusion of 'my daydream' is broken, you step back and assess what you are looking at, and if you are motivated (by instinctual emotional involvement dependent on your own personal desires), you then choose to participate and enjoy the illusion more fully. The peepshow carries less experiential baggage as a medium, and so the viewer is more inclined to allow the illusory world to exist on its own terms.

Leclaire's concept of indications of immediacy also helps to explain some of the most compelling elements of the PSYCHÉ experience: those moments when objects were so real that they threatened injury and produced instinctive physical reactions. This sense of reality is completely unquestioned at the time, and it is only later that illusion is exposed. Perception can be an issue of self-preservation; when if thrown into a vital situation we need to respond without hesitation (Leclaire, 2003, p. 337), and so if indications of immediacy are strong enough we will act before there is enough time for indications of reality to be established. For a brief time reality cannot even be considered or questioned, and so in a way is assumed. This produces a powerfully compelling, if momentary, completion of the aesthetic illusion.
Unfortunately, this is not a sensation that can be sustained. For one thing, repeated vital situations would be exhausting and unrealistic for most representations, but also this experience eludes the sense of the alternate reality that provides the safety net of the aesthetic illusion. The viewer needs a sense of 'other world' to feel safe in the illusion and remember that this is only a dream.

So while for aesthetic illusion to be complete the viewer must believe in the 'real world' represented, the safety net of 'this is only a dream' relies on the simultaneous belief that the actual world of the viewer is in fact the real world. It is the role of the artist to carefully manage these conflicting realities, harnessing the motivations and desires of the ego allow the realities of the two worlds to co-exist.

\section{CONCLUSIONS: DEVELOPMENT OF BRUNEL PEEPSHOW PROTOTYPE}

In this chapter the conclusions from the analysis of case studies Earthquake and PSYCHÉ, become initial concepts for the development of a prototype for a contemporary peepshow of the Brunel Tunnels. Producing and maintaining aesthetic illusion is prioritised over educational content, since success of the illusion will achieve immediate engagement and motivate the viewer to maintain this interest.

\subsection{Fostering infantile fantasies}

The fantasy of omnipotence will be the main feature of this installation, producing instant and primitive pleasure:

- In terms of content the theme will develop from various events in the history of the tunnels, and transport the viewer forward (or backward) through time.

- The viewer will gain access to worlds usually hidden, both temporal and spatial, that will transform according to his/her wishes.

- Wish fulfilment will rely on careful management of expectations through context of installation, and narrative development supported by audio narration.

- The fantasy provided by the representational content is only part of the illusion of omnipotence, and may even be secondary to the spatial illusion produced by light, shadow, movement, lenses and mirrors. This transformation of a small space into a vast portable world produces an almost god-like sense of omnipotence. This illusion may be supported by the use of new technologies that produce an 
extended sense of space, such as 3D animation and stereoscopy.

- Secrecy and intimacy need to be maintained, so to keep the viewer (and the view) private the installation should be screened off in some way.

- Interactivity will reinforce the sense of omnipotence, by assisting the viewer to transform the illusion according to wishes in a very compelling way. This needs to be very discreet so that the viewer does not become a part of the spectacle, and the experience is still a private pleasure rather than a test of abilities: use sensors rather than manual input devices, and make interactivity intuitive.

\subsection{Recathexis}

The movement and interactivity of virtual reality technology can produce extremely compelling moments, where familiar experiences are revisited:

- The peepshow will include elements that capture the vitality of the virtual reality experience, adding a sense of real world familiarity and making the illusion more compelling.

- These elements will include projected stereoscopic footage, and aim to place the viewer in a situation of real-life urgency, e.g. a train rushing through the tunnel.

- Use of close-ups here could also make this more intimate and 'immediate' than the usual distance of the wide, long shot employed by the traditional peepshow.

\subsection{This is my daydream}

The viewer needs to take ownership of the dream inside the peepshow, forgetting the existence of the artist, and this is largely accomplished by the personalisation of the infantile fantasies already described. Other factors can help the viewer to forget the hand of the artist:

- Methods of production should sometimes be transparent, so that the viewer can easily deconstruct and demystify the process.

- Elements of the installation could be removable through slots.

- Transparent panels could reveal the inner workings of the installation.

- Hand made imagery and simple accessible materials should be used.

- Both cut outs and 3D imagery can be used to facilitate 'seeing-in'.

- Viewers could 'own' the illusion in a more literal way, by adding their own imagery, or by purchasing simplified portable versions of the peepshow.

\subsection{Real person in a real world}

By its immersive nature the peepshow is missing a vital element of the aesthetic illusion: the protagonist. The protagonist is important in terms of identification and personalisation of the fantasy, and also vital as a proxy to shoulder the anxieties provoked by this infantile indulgence. It is important to overcome this so that there is enough instinctual emotional involvement to motivate the viewer to believe in the reality of the illusion.

- Audio narration will play an important part in supporting identification and emotional engagement, rather than being informative or educational.

- Vital moments, like those described in PSYCHÉ, can be used to produce a sense of 'immediacy' that engenders belief in the 'reality' of the illusion. Although these moments may be very compelling, it is important to remember that the intensity of emotion may cause extreme anxiety can lead to the destabilisation or complete break down of the overall aesthetic illusion. This needs to be considered and managed in the production.

- Use of projected moving image (film and CGI), and diegetic sound will produce the projective illusion, and help promote belief in the reality of the illusory world.

- The context of the peepshow can be used to support the sense of wish fulfilment that will increase the intensity of the pleasure of omnipotence, and this in turn motivates the viewer to invest in the belief in the reality of the illusory world. Placing the installation alongside the original peepshow and making sure that the viewer has relevant historical information beforehand, should help to set up the desire to see this history re-enacted through time travel.

- Context is also important in terms of viewer expectations of the media. The peepshow should not be presented as a virtual reality experience, so the viewer can enjoy the illusion on its own terms, without the burden of the living up to the CGI of science fiction.

\section{REFERENCES}

Allen, R. (1993) Representation, Illusion, and the Cinema. Cinema Journal, vol. 32, no.2, Winter, pp. 21-48. 
Balter, L. (1999) On The Aesthetic Illusion Journal of the American Psychoanalytic Association, vol.47, pp. 1293-1333.

Balter, L. (2001) 'Magic and the Aesthetic Illusion', Journal of the American Psychoanalytic Association, vol.50, pp. 1163-1196.

Balzer, R. (1998) Peepshows: A Visual History, New York: Harry N. Abrams, Inc.
Leclaire, M. (2003) The 'mad scientists':

Psychoanalysis, dream and virtual reality. International Journal of Psychoanalysis, vol. 84, pp. 331-346.

Stafford, B.M. and Terpak, F. (2001) Devices of Wonder: From the World in a Box to Images on a Screen, Los Angeles: Getty Research Institute. 